\title{
MINI-SYMPOSIUM
}

\section{Embolic protection devices}

\author{
G Sangiorgi, A Colombo
}

Heart 2003;89:990-992

$\mathrm{P}$ ercutaneous intervention for the treatment of coronary and peripheral atherosclerotic disease has become a well established technique, and has been recently extended also to the carotid arena. However, distal embolisation of particulate matter, including plaque debris such as fibrin, necrotic atheromatous core, foam cells, cholesterol clefts, and thrombus, ${ }^{1}$ at the time of balloon inflation or stent deployment, complicate percutaneous mechanical interventions more often than had been recognised before. The risk of distal embolisation is now considered significant in carotid arteries, ${ }^{2}$ degenerated saphenous vein graft, and in thrombotic lesions characterising the patient affected by acute coronary syndromes. ${ }^{3-5}$ The process of plaque embolisation catalyses a complex interaction also involving microvascular spasm and thrombosis. This often results in diminished blood flow to the distal vascular bed, potentially complicated by periprocedural ischaemia and/or infarction or stroke. ${ }^{67}$ In particular, the risk of distal embolisation is especially high in degenerated saphenous vein grafts, with the "no reflow" phenomenon being reported in up to $31.8 \%$ of cases during treatment of thrombotic lesions and in up $7.9 \%$ of cases with no thrombus present. $^{8}$ Although large particles $(>100 \mu \mathrm{m})$ may obstruct large, epicardial vessels, very small particles, as little as 15-50 $\mu \mathrm{m}$, can also obstruct the microvascular bed causing microinfarcts and left ventricular dysfunction. In the setting of acute myocardial infarction, Ito and associates ${ }^{9}$ detected by myocardial contrast echocardiography a substantial "no reflow" area, potentially related to distal embolisation of atherosclerotic debris in $37 \%$ of patients with TIMI-3 flow shortly after reperfusion treatment. Those "infarctlets", indicated by an increase in periprocedural creatine kinase$\mathrm{MB}$, have been recently associated with worse outcome at one year follow up, even in patients without any apparent procedure or in-hospital complications. ${ }^{10}$

Different approaches have been attempted in the past to reduce distal embolisation, including intracoronary administration of urokinase, ${ }^{11}$ extraction coronary atherectomy, ${ }^{12}$ directional coronary atherectomy, ${ }^{13}$ laser angioplasty, ${ }^{14}$ ultrasound thrombolysis, ${ }^{15}$ and AngioJet rapid thrombectomy. ${ }^{16}{ }^{17}$ The results, however, were not considered to be satisfactory in terms of achieving a significant reduction in distal embolisation.

Over the last few years, several distal protection devices have been introduced to allow the capture and retrieval of friable, lipid-rich plaque constituents released after percutaneous interventional procedures, before they lodge in the distal microcirculation. Currently available technologies for embolic protections have focused either on conduit occlusion (proximal or distal) with subsequent aspiration or on distal filter capture debris (table 1).

\section{BALLOON OCCLUSION DEVICES}

The PercuSurge GuardWire, the device with the most clinical use, is a temporary distal occlusion system that comprises three components: (1) the GuardWire temporary occlusion catheter containing a central lumen connected to a low pressure distal occlusion elastomeric balloon incorporated into the tip and with a diameter ranging from 3-6 $\mathrm{mm}$ - the low profile of the deflated balloon facilitates lesion crossing providing protection from distal embolisation; (2) the MicroSeal adapter that controls the opening and closure of a proximal valve in the GuardWire, allowing inflation and deflation of the distal occlusion balloon; and (3) the Export aspiration catheter that consists of a 5 French monorail catheter connected to an evacuated $20 \mathrm{ml}$ syringe used to remove thrombotic debrisafter that, the GuardWire balloon is deflated and the anterograde flow is restored. One of the most important limitations of this distal balloon occlusion device is that it may cause distal ischaemia that may not be tolerated by some patients. In addition, filter preparation is cumbersome and angiography cannot be performed while the distal balloon is inflated, making assessment of the artery and stent placement more difficult.

Preliminary encouraging results with the PercuSurge GuardWire $^{18}$ have been confirmed in the SAFER (saphenous vein graft angioplasty free of emboli randomized) trial conducted in the USA at 47 sites. $^{19}$ The trial randomly allocated 406 patients to stenting with embolic protection and 396 patients to standard care without embolic protection during vein graft percutaneous coronary intervention. The primary end point, a composite of death, myocardial infarction, emergency bypass or target lesion revascularisation at 30 days, was significantly reduced in the group of patients assigned to treatment with the protection device compared to patients assigned to standard care (9.6\% $v 16.5 \%)$. This $42 \%$ relative reduction in major adverse cardiac events (MACE) was driven by reductions in myocardial infarction $(8.6 \% \mathrm{v}$ $14.7 \%$ ) and no reflow phenomenon (3\% v 9\%). Interestingly, although adjunctive prophylactic treatment was administered (non-randomized allocation) to $\geqslant 60 \%$ of patients enrolled in the trial, a similar magnitude of MACE reduction was provided by mechanical embolic protection whether glycoprotein IIb/IIIa inhibition was administered ( $18.1 \%$ to $10.8 \%$ ) or not $(14.1 \%$ to $8.0 \%)$, attesting to the diverse pathogenesis of atheroembolism and the prominent importance of mechanical microvascular obstruction. Similarly, the feasibility and safety of carotid angioplasty using the PercuSurge system has been determined in different series such as the CAFÉ USA and the SHELTER registries with different success and complications rate. ${ }^{2021}$

\section{FILTER DEVICES}

The AngioGuard device consists of an angioplasty guide wire with an expandable porous filter at the distal tip. The filter is made of a thin, porous polymeric membrane supported by a fine metal skeleton. After crossing the lesion and reaching the

Abbreviations: CEA, carotid endarterectomy; GUARD, saphenous vein graft intervention using AngioGuard for reduction of distal embolization; MACE, major adverse cardiac events; SAFER, saphenous vein graft angioplasty free of emboli randomized; SAPPHIRE, study of angioplasty with protection in patients at high risk for endoarterectomy; TIMI, thrombolysis in myocardial infarction 


\begin{tabular}{|c|c|c|c|c|c|c|c|c|}
\hline $\begin{array}{l}\text { Device } \\
\text { type }\end{array}$ & Device name & System components & Manufacturer & Material & Guidewire & Pore size & $\begin{array}{l}\text { Guide } \\
\text { compatibility }\end{array}$ & Indication \\
\hline \multirow[t]{2}{*}{$\begin{array}{l}\text { Proximal } \\
\text { occlusion }\end{array}$} & Arteri-A-Parodi & $\begin{array}{l}\text { PEAC balloon catheter, } \\
\text { ECA occlusion balloon, } \\
\text { arterial-venous shunt } \\
\text { w/filter }\end{array}$ & Arteria Inc & PTFE/PU & 0.035 inch & NA & 10 French & Carotid \\
\hline & MO. MA & $\begin{array}{l}\text { PEAC balloon catheter, } \\
\text { ECA occlusion balloon, } \\
\text { arterial-venous shunt } \\
\text { w/filter }\end{array}$ & Invatec & & 0.035 inch & NA & 9-11 French & Carotid \\
\hline \multirow{2}{*}{$\begin{array}{l}\text { Distal } \\
\text { occlusion }\end{array}$} & \multirow{2}{*}{$\begin{array}{l}\text { GuardWire } \\
\text { (MDT-Percusurge) }\end{array}$} & \multirow{2}{*}{$\begin{array}{l}\text { Guardwire (wire + balloon), } \\
\text { inflation device, Export } \\
\text { aspiration catheter }\end{array}$} & \multirow{2}{*}{ Medtronic } & Hollow & 0.014 inch & \multirow[t]{2}{*}{ N/A } & \multirow[t]{2}{*}{8 French } & \multirow{2}{*}{$\begin{array}{l}\text { Peripheral, carotid, } \\
\text { coronary }\end{array}$} \\
\hline & & & & Hypotube & 0.018 inch & & & \\
\hline \multirow[t]{8}{*}{$\begin{array}{l}\text { Filter } \\
\text { device }\end{array}$} & AngioGuard XP & $\begin{array}{l}\text { Filter, deployment sheath, } \\
\text { capture sheath, torque } \\
\text { device }\end{array}$ & Cordis & PU/Nitinol & 0.014 inch & $100 \mu \mathrm{m}$ & 8 French & $\begin{array}{l}\text { Peripheral, carotid, } \\
\text { coronary }\end{array}$ \\
\hline & Bsc-FilterWire EX & $\begin{array}{l}\text { Delivery catheter, filter, } \\
\text { capture sheath }\end{array}$ & Embolic protection & Nitinol & 0.014 inch & $80 \mu \mathrm{m}$ & 4 French & Carotid, coronary \\
\hline & Accunet & $\begin{array}{l}\text { Delivery catheter, filter, } \\
\text { capture sheath }\end{array}$ & Guidant & PU/Nitinol & 0.014 inch & $120 \mu \mathrm{m}$ & & Carotid, coronary \\
\hline & $\begin{array}{l}\text { Mednova, } \\
\text { Neuroshield }\end{array}$ & $\begin{array}{l}\text { Delivery catheter, filter, } \\
\text { capture sheath }\end{array}$ & Abbott & PU/Nitinol & $\begin{array}{l}0.014 \text { inch } \\
0.018 \text { inch }\end{array}$ & $150 \mu \mathrm{m}$ & 9 French & $\begin{array}{l}\text { Peripheral, carotid, } \\
\text { coronary }\end{array}$ \\
\hline & $\begin{array}{l}\text { Mednova } \\
\text { MDT-Filter }\end{array}$ & Delivery catheter, filter & Medtronic & Nitinol & 0.014 inch & $100 \mu \mathrm{m}$ & 7 French & Peripheral, coronary \\
\hline & E-Trap/E-Sack & $\begin{array}{l}\text { Delivery catheter, filter, } \\
\text { capture sheath }\end{array}$ & Metamorphic & Nitinol & 0.014 inch & $100 \mu \mathrm{m}$ & 6 French & Peripheral, coronary \\
\hline & TRAP & $\begin{array}{l}\text { Delivery catheter, filter, } \\
\text { capture sheath }\end{array}$ & Microvena & $\begin{array}{l}\text { Nitinol wire, } \\
\text { woven basket }\end{array}$ & 0.014 inch & & 6 French & Peripheral \\
\hline & Sulzer-Intraguard & $\begin{array}{l}\text { Delivery catheter, filter, } \\
\text { capture sheath }\end{array}$ & IntraTherapeutics & Nitinol & 0.014 inch & $100 \mu \mathrm{m}$ & 6 French & Peripheral \\
\hline
\end{tabular}

distal site, the filter is expanded and routine angioplasty is performed. As the blood passes through the filter, emboli are captured in the filter. At the end of the procedure, the filter is collapsed, trapping embolic debris, which are retrieved by retracting the wire into a retrieving catheter. As opposed to the balloon occlusion device that produces complete interruption of anterograde flow and does not allow perfusion during the procedure, the AngioGuard ensures normal blood flow continuously. Practical advantages of this filter include its ease of use, good visibility, and crossing profile. A disadvantage is represented by a fairly stiff retrieval pod with potential difficulties in crossing the stent during filter withdrawal. At present, the AngioGuard filter device is still under investigation in the USA for both coronary and carotid percutaneous interventions. In particular, the SAPPHIRE (study of angioplasty with protection in patients at high risk for endoarterectomy) trial has been designed to determine the benefits of stenting with the AngioGuard device compared to surgical carotid endarterectomy $(\mathrm{CEA})^{22}$ in symptomatic patients with carotid stenosis $\geqslant 50 \%$ and asymptomatic patients with carotid stenosis $\geqslant 80 \%$. Preliminary results showed that 30 days MACE (death/stroke/acute myocardial infarction) was significantly lower in the stent group compared to the CEA group $(5.8 \% v 12.6 \%$, p < 0.004$)$. The GUARD (saphenous vein graft intervention using AngioGuard for reduction of distal embolization) trial is still ongoing and will evaluate the efficacy of this device in a study population of 800 patients submitted for percutaneous coronary intervention.

The FilterWire EX (Boston Scientific, Natick, Massachusetts, USA) is a low profile ( $<3.5$ French) "fish-mouth" opening distal polyurethane filter with $80 \mu \mathrm{m}$ diameter pore holes mounted on a 0.014 inch steerable angioplasty wire via a "spinner tube" which permits independent $360^{\circ}$ rotation and steering of the wire. Pores allow anterograde blood flow while providing distal protection. The filter is attached to a radiopaque nitinol loop that is self expandable, allowing for complete contact of the filter against the arterial wall and facilitating fluoroscopic visualisation. The collapsed filter (3.9 French crossing profile) is placed distal to the lesion and deployed by retracting the delivery sheath. The filter is then closed with the delivery/retrieval sheath after the procedure and withdrawn. Initial reports regarding feasibility, safety, and clinical efficacy are promising. Stone and associates ${ }^{23}$ have reported a large multicentre experience with this device in a sequential two phase investigation conducted on 308 lesions in 278 saphenous vein grafts. Use of this device resulted in a low rate of periprocedural adverse events compared to historical controls (30 day rates of MACE occurred in $21.3 \%$ of patients in phase I, which was reduced to $11.3 \%$ in phase II, despite nearly identical patient and vein graft characteristics). This reduction was mainly caused by a decrease in Q wave and non-Q wave myocardial infarction. More recently, Grube and collaborators ${ }^{24}$ have reported their experience with the FilterWire EX device in 35 consecutive patients undergoing elective carotid stenting at six centres. The FilterWire was delivered and deployed successfully in all cases, embolic debris was retrieved from $74 \%$ of procedures, and the 30 day rate of MACE (death, major or minor stroke) was $0 \%$

The MedNova NeuroShield (MedNova Inc, Galway, Ireland) consists of a 0.014 inch guidewire with a polyurethane filter mounted at the distal end. The system requires both a delivery and a retrieval catheter that in the latest generation are shorter and more flexible. Two large holes at the proximal end of the filter allow emboli to enter. The filter contains a pre-shaped nitinol expansion system that facilitates fluoroscopic visualisation, accurate deployment, and wall apposition. The filter guidewire is placed within the delivery catheter and is passed through the target lesion, the delivery catheter is withdrawn, the filter is deployed and, at the end of the interventional procedure, the retrieval catheter is used to envelop the filter. At this point, the entire device and its embolic contents are retracted. 


\section{CATHETER OCCLUSION DEVICES}

The Parodi Anti-Emboli System (PAES; ArteriaA Medical Science, Inc, San Francisco, California, USA) and the MO.MA system are guiding catheters with a proximal occlusion balloon attached at the distal end. Both devices provide protection by reversing blood flow from the internal carotid artery into the sheath by means of negative pressure gradient through the guiding catheter. The external carotid artery is also occluded to avoid flow travelling from the external one back up the internal one. Although this elegant technique allows protection before the lesion is crossed and it can be used also in tight and tortuous vessels, the systems are bulky (11 French sheaths and 10 French guiding catheter are required) and there is a potential for damage of the artery at the site of balloon inflation. However, several cases have been reported with $100 \%$ successful deployment and no ipsilateral embolic events. The results of an ongoing European registry with the MO.MA device are shortly awaited.

\section{LIMITATIONS}

In general, each system has its own intrinsic limitations, and protection provided by these devices is far from "complete". ${ }^{25}$ Causes of incomplete embolic protection include device crossing profile (larger profiles may lead to embolisation), incomplete filter apposition or conduit occlusion (especially in bending segments of the vessel), lack of protection of secondary branches, incomplete aspiration, filter pore size (either too large or small), device mediated vessel wall trauma, side branches ("backwash" during occlusion versus siphoning of debris during filter), and delayed platelet-white cell embolisation from the target site. In addition, balloon occlusion-type devices may cause distal ischaemia that may not be tolerated by some patients, and an aspiration catheter may not retrieve all the particles trapped in the artery. Finally, filter devices have a finite lower limit in the size of particles that can be captured and smaller particles can still get through the filter. A novel approach currently under evaluation that may circumvent many of these limitations involves proximal conduit occlusion (without crossing the lesion) and pressure driven aspiration from a catheter to evacuate particulate debris irrespective of particle size. This device (Proxis, Velocimed) also permits distal administration of drugs, such as vasodilators or cardioplegic or nutrient solutions, thus providing a double, pharmacomechanical approach to address the complex pathophysiologic process of embolisation.

\section{CONCLUSION}

Although several technical development and material improvements have been made in the construction of the distal protection devices, future iterative engineering is required to obtain an atraumatic system, with very low profile, high torqueability, and an ability to capture all of the plaque debris. Ultimately, only when the clinical efficacy of these devices has been clearly demonstrated in large clinical trials, involving patients with different risk profiles, will embolic protection systems be ultimately incorporated into the daily practice of percutaneous coronary and peripheral interventions.

\section{Authors' affiliations}

G Sangiorgi, A Colombo, Columbus Hospital, Milan, Italy

Correspondence to: Antonio Colombo, MD, Columbus Hospital, Via Buonarroti 48 - 20145, Milan, Italy; info@emocolumbus.it

\section{REFERENCES}

1 Webb JG, Carere RG, Virmani R, et al. Retrieval and analysis of particulate debris after saphenous vein graft intervention. J Am Coll Cardiol 1999:34:468-75.

2 Jordan WD, Jr., Voellinger DC, Doblar DD, et al. Microemboli detected by transcranial Doppler monitoring in patients during carotid angioplasty versus carotid endarterectomy. Cardiovasc Surg 1999;7:33-8.

3 MacDonald RG, Feldman RL, Conti CR, et al. Thromboembolic complications of coronary angioplasty. Am J Cardiol 1984;54:916-17.

4 Weyne AE, Heyndricks GR, Vandekerckhove YR. Embolization complicating coronary angioplasty in the presence of intracoronary thrombus. Clin Cardiol 1986:9:463-5.

5 Cameron J, Buchbinder M, Wexler L, et al. Thromboembolic complications of percutaneous transluminal coronary angioplasty for myocardial infarction. Cathet Cardiovasc Diagn 1987;13:100-6.

6 Califf RM, Abdelmeguid AE, Kuntz RE, et al. Myonecrosis after revascularization procedures. J Am Coll Cardiol 1998:31:241-51.

7 Koch KC, vom Dahl J, Kleinhans E, et al. Influence of a platelet GPIlb/IIla receptor antagonist on myocardial hypoperfusion during rotational atherectomy as assessed by Tc- $99 \mathrm{~m}$ sestamibi scintigraphy. J Am Coll Cardiol 1999:33:998-1004.

8 Lefkovits J, Holmes DR, Califf RM, et al. Predictors and sequelae of distal embolization during saphenous vein graft intervention from the CAVEAT-II trial. Coronary angioplasty versus excisional atherectomy trial. Circulation 1995:92:734-40.

9 Ito $\mathbf{H}$, Maruyama A, Iwakura K, et al. Clinical implications of the 'no reflow' phenomenon. A predictor of complications and left ventricular remodeling in reperfused anterior wall myocardial infarction. Circulation 1996;93:223-8

10 Hong MK, Mehran R, Dangas G, et al. Creatine kinase-MB enzyme elevation following successful saphenous vein graft intervention is associated with late mortality. Circulation 1999;100:2400-5.

11 Hartmann J, McKeever L, Teran J. Prolonged infusion of urokinase for re-canalization of chronically occluded aortocoronary bypass grafts. Am J Cardiol 1988:61:189-91.

12 Safian RD, Grines CL, May MA, et al. Clinical and angiographic results of transluminal extraction coronary atherectomy in saphenous vein bypass grafts. Circulation 1994;89:302-12.

13 Holmes DRJ, Topol EJ, Califf RM, et al. TC-I. A multicenter, randomized trial of coronary angioplasty versus directional atherectomy for patients with saphenous vein bypass graft lesions. Circulation 1995;91:196674

14 Bittl JA, Sanborn TA, Yardley DE, et al. Predictors of outcome of percutaneous excimer laser coronary angioplasty of saphenous vein bypass graft lesions. The percutaneous excimer laser coronary angioplasty registry. Am J Cardiol 1994;74:144-8.

15 Rosenschein U, Gaul G, Erbel R, et al. Percutaneous transluminal therapy of occluded saphenous vein grafts: can the challenge be met with ultrasound thrombolysis? Circulation 1999;99:26-9.

16 Ramee SR, Schatz RA, Carrozza JP, et al. I Pilot study of the Possis coronary AngioJet thrombectomy catheter. Circulation 1996;94(suppl):3622

17 Hamburger JN, Serruys PW. Treatment of thrombus containing lesions in diseased native coronary arteries and saphenous vein bypass grafts using AngioJet rapid thrombectomy system. Herz 1997;22:318-21.

18 Carlino M, De Gregorio J, Di Mario C, et al. Prevention of distal embolization during saphenous vein graft lesion angiolasty. Experience with a new temporary occlusion and aspiration system. Circulation 1999:99:3221-3.

19 Baim DS, Wahr D, George B, et al, on behalf of the Saphenous vein graft Angioplasty Free of Emboli Randomized (SAFER) Trial Investigators. Randomized trial of a distal embolic protection device during percutaneous intervention of saphenous vein aorto-coronary grafts. Circulation 2002; 105:1285-90.

20 Henry $M$, Amor $M$, Henry l, et al. Carotid stenting with cerebral protection: first clinical experience using the PercuSurge GuardWire system. J Endovasc Surg 1999;6:321-31.

21 Ohki T, Veith FJ, Grenell S, et al. Initial experience with cerebral protection devices to prevent embolization during carotid artery stenting. J Vasc Surg 2002;36:1 175-85.

22 Hobson RW. Status of carotid angioplasty and stenting trials. J Vasc Surg 1998;27:791.

23 Stone GW, Rogers C, Ramee SR, et al. Distal filter protection during saphenous vein graft stenting: technical and clinical correlates of efficacy. J Am Coll Cardiol 2002;40: 1882-8.

24 Grube E, Colombo A, Hauptmann E, et al. Initial multicenter experience with a novel distal protection filter during carotid artery stent implantation. Cathet Cardiovasc Intervent 2003;58:139-46.

25 Muller-Hulsbeck S, Jahnke T, Liess C, et al. In vitro comparison of four cerebral protection filters for preventing human plaque embolization during carotd interventions. J Endovasc Ther 2002;9:793-802. 